\title{
Practical Quantitative Biomedical Applications of MALDI-TOF Mass Spectrometry
}

\author{
Martin Bucknall and Kim Y. C. Fung \\ Ray Williams Biomedical Mass Spectrometry Facility, University of New South Wales, Sydney, Australia
}

\author{
Mark W. Duncan \\ Department of Pharmaceutical Sciences, School of Pharmacy, University of Colorado Health Sciences Center, \\ Denver, Colorado, USA
}

\begin{abstract}
Matrix-assisted laser desorption ionization time-of-flight mass spectrometry (MALDI-TOFMS) is used to obtain fast and accurate determinations of molecular mass, but quantitative determinations are generally made by other techniques. In this study we illustrate the practical utility of automated MALDI-TOFMS as a tool for quantifying a diverse array of biomolecules covering an extensive molecular weight range, and present in biological extracts and fluids. Growth hormone was measured in rat pituitary tissue; insulin in human pancreatic tissue; homovanillic acid in human urine; and LVV-hemorphin-7, epinephrine and norepinephrine in human adrenal and pheochromocytoma tissues. Internal standards including compounds of similar molecular weight, structural analogs or isotopomers were incorporated into each analysis. We report on the current practical limitations of quantitative MALDI-TOFMS and highlight some of the potential benefits of this technique as a quantitative tool. (J Am Soc Mass Spectrom 2002, 13, 1015-1027) @ 2002 American Society for Mass Spectrometry
\end{abstract}

S ince its inception and commercial availability, the versatility of MALDI-TOFMS has been demonstrated convincingly by its extensive use for qualitative analysis. For example, MALDI-TOFMS has been employed for the characterization of synthetic polymers [1, 2], peptide and protein analysis [3-5], DNA and oligonucleotide sequencing [6-8], and the characterization of recombinant proteins $[9,10]$. Recently, applications of MALDI-TOFMS have been extended to include the direct analysis of biological tissues and single cell organisms with the aim of characterizing endogenous peptide and protein constituents [11-18].

The properties that make MALDI-TOFMS a popular qualitative tool-its ability to analyze molecules across an extensive mass range, high sensitivity, minimal sample preparation and rapid analysis times-also make it a potentially useful quantitative tool. MALDITOFMS also enables non-volatile and thermally labile molecules to be analyzed with relative ease. It is therefore prudent to explore the potential of MALDI-TOFMS for quantitative analysis in clinical settings, for toxicological screenings, as well as for environmental analysis. In addition, the application of MALDI-TOFMS to the quantification of peptides and proteins is particularly relevant. The ability to quantify intact proteins in

Published online July 24, 2002

Address reprint requests to Dr. M. W. Duncan, Department of Pharmaceutical Sciences, School of Pharmacy, C238, University of Colorado Health Sciences Center, Denver, CO 80262, USA. E-mail: mark.duncan@uchsc.edu biological tissue and fluids presents a particular challenge in the expanding area of proteomics and investigators urgently require methods to accurately measure the absolute quantity of proteins.

While there have been reports of quantitative MALDI-TOFMS applications, there are many problems inherent to the MALDI ionization process that have restricted its widespread use [19-39]. These limitations primarily stem from factors such as the sample/matrix heterogeneity that is believed to contribute to the large variability in observed signal intensities for analytes, the limited dynamic range due to detector saturation, and difficulties associated with coupling MALDITOFMS to on-line separation techniques such as liquid chromatography. Combined, these factors are thought to compromise the accuracy, precision, and utility with which quantitative determinations can be made.

Because of these difficulties, practical examples of quantitative applications of MALDI-TOFMS have been limited. Most of the studies to date have focused on the quantification of low mass analytes, in particular, alkaloids or active ingredients in agricultural or food products [40-45], whereas other studies have demonstrated the potential of MALDI-TOFMS for the quantification of biologically relevant analytes such as neuropeptides, proteins, antibiotics, or various metabolites in biological tissue or fluid [23, 27-29, 33, 35, 38, 46].

In earlier work we were able to show that linear calibration curves could be generated by MALDITOFMS provided that an appropriate internal standard 
was employed [33]. This standard can "correct" for both sample-to-sample and shot-to-shot variability. Nevertheless, our work was restricted to low mass analytes: The catecholamines, acetylcholine, and a peptide. We were severely hampered by the limited mass resolution of our previous instrument (Finnigan Lasermat 2000), so it was only in those few instances where we could completely resolve the analyte and internal standard that satisfactory quantification was achievable. Stable isotope labeled internal standards (isotopomers) gave the best result; when we employed a structural analog as the internal standard it was at the expense of both accuracy and precision.

With the marked improvement in resolution available on modern commercial instruments, primarily because of delayed extraction [47, 48], the opportunity to extend quantitative work to other examples is now possible; not only of low mass analytes, but also biopolymers. Of particular interest to us is the prospect of absolute multi-component quantification in biological samples (e.g., proteomics applications).

This study explores the utility of MALDI-TOFMS for the quantification of five different biomolecules in biological tissue or fluid: homovanillic acid in human urine; catecholamines (epinephrine and norepinephrine) in human adrenal tissue; insulin in human pancreatic tissue; LVV-hemorphin-7 in human adrenal gland; and growth hormone in the rat pituitary gland. These samples cover a wide mass range and represent practical examples of quantification in complex realworld biological matrices.

\section{Methods}

\section{Materials and Reagents}

Trifluoroacetic acid (TFA), norepinephrine hydrochloride, homovanillic acid (HVA), $\beta$-lactoglobulin, 4-hydroxy-3-methoxycinnamic acid (ferulic acid), porcine insulin, and bovine serum albumin (BSA) were all obtained from Sigma Chemical Co. (Sydney, NSW, Australia). Recombinant methionyl rat growth hormone (metrGH, >97\% monomer; 21,943 Da) was purchased from Gropep Pty. Ltd. (Adelaide, SA, Australia). Epinephrine, $\alpha$-cyano-4-hydroxycinnamic acid (4HCCA), 2,5-dihydroxybenzoic acid (DHB), and 3,5-dimethoxy-4-hydroxycinnamic acid (sinapinic acid) were obtained from Aldrich Chemical Co., Inc. (Milwaukee, WI). Caffeic acid was purchased from ICN Biomedical Inc. (Aurora, OH). Synthetic rat LVV-hemorphin-7 (H-LVVYPQWTQRY-OH) and synthetic human LVV-hemorphin-7 (H-LVVYPWTQRF-OH) were custom synthesized by Chiron Technologies Pty., Ltd. (Clayton, Victoria, Australia). DLNorepinephrine- $\alpha \alpha \beta-\left[{ }^{2} \mathrm{H}_{3}\right] \cdot \mathrm{HCl}$ and 4-hydroxy-3methoxyphenyl-2,5,6- $\left[{ }^{2} \mathrm{H}_{3}\right]$-acetic-2,2- $\left[{ }^{2} \mathrm{H}_{2}\right]$ acid $\left(\left[{ }^{2} \mathrm{H}_{5}\right]-\right.$ HVA) were obtained from Merck and Co., Inc., (Rahway, NJ). DL-Epinephrine- $\alpha \alpha \beta-\left[{ }^{2} \mathrm{H}_{3}\right]$ was a generous gift from Cambridge Isotope Laboratories (Andover, MA). Crystalline human insulin monocompo- nent (CSL, Melbourne, Australia) was a gift from Assoc. Professor B. E. Tuch, Prince of Wales Hospital, Sydney, Australia. All other solvents and reagents were of the highest grade available, and were obtained from commercial suppliers. Water was purified by a Millipore water purification system and had a resistivity $>18$ $\mathrm{M} \Omega / \mathrm{cm}$.

Sep-Pak C18 Cartridges (Waters Corporation, Milford, MA) were preconditioned with $\mathrm{CH}_{3} \mathrm{CN}: \mathrm{H}_{2} \mathrm{O}$ :TFA $(80: 20: 0.1 ; 5 \mathrm{~mL})$, and washed with dilute aqueous TFA $(0.1 \% ; 10 \mathrm{~mL})$ prior to use.

\section{Sample Preparation}

MALDI matrices and sample plate preparation. Sinapinic acid $(5 \mathrm{mg} / \mathrm{mL}), 4 \mathrm{HCCA}(5 \mathrm{mg} / \mathrm{mL})$, and caffeic acid $(10 \mathrm{mg} / \mathrm{mL})$ were prepared in $\mathrm{CH}_{3} \mathrm{CN}: \mathrm{H}_{2} \mathrm{O}$ :TFA (80:20: $0.1)$. Ferulic acid $(5 \mathrm{mg} / \mathrm{mL})$ and DHB $(10 \mathrm{mg} / \mathrm{mL})$ were prepared in $100 \% \mathrm{CH}_{3} \mathrm{CN}$.

All of the samples analyzed in this study were mixed with the MALDI matrix solution immediately prior to analysis. For those samples stored frozen, fresh dilutions were made immediately before analysis. Aliquots $(0.5-1 \mu \mathrm{L})$ were applied to between 10 and 20 sample positions on a 100 position flat MALDI target (Perseptive Biosystems, Framingham, MA). Samples were dried at room temperature and pressure. The number of target positions used for each sample was chosen to provide a suitable compromise between precision and analytical speed.

Preparation of tissue extracts. Tissue slices (ca. 5-10 mg) were shaved from frozen sections and accurately weighed. The samples were macerated mechanically in aqueous TFA $(0.1 \% ; 10 \mathrm{mg} / \mathrm{mL})$ and an ultrasonic probe was then employed to completely disrupt the residual tissue. Internal standards were added and the sample mixed thoroughly. Samples were then centrifuged $(14,000 \mathrm{~g}, 15 \mathrm{~min})$ and the supernatant collected and stored.

ANALYSIS OF GROWTH HORMONE IN RAT PITUITARY TISSUE. Male Sprague-Dawley rats $>300$ g body weight) were decapitated and their pituitary glands (ca. $15-20 \mathrm{mg}$ ) were surgically removed and stored at -20 ${ }^{\circ} \mathrm{C}$ until required. Whole glands were extracted in aqueous TFA $(0.1 \% ; 1.5 \mathrm{~mL})$, and the internal standard $\beta$-lactoglobulin $(15 \mathrm{nmol})$ was then added. Standard solutions containing met-rGH $(0,10,20,40,100,150$, and $200 \mathrm{pmol})$ and $\beta$-lactoglobulin (100 pmol) were prepared in aqueous TFA $(0.1 \% ; 20 \mu \mathrm{L})$ to generate the standard curve. Standard solutions and samples were then diluted 1:5 in caffeic acid solution before analysis. Met-rGH was used in place of human growth hormone (hGH) in the standards because it was readily accessible. We assumed that equal amounts of rat growth hormone $(\mathrm{rGH})$ and N-terminal methionyl rat growth hormone (met-rGH) on target yield the same ion current. 
ANALYSIS OF INSULIN IN HUMAN PANCREATIC TISSUE. Control human pancreatic tissue was obtained from cadavers $(n=2)$ and frozen at $-20{ }^{\circ} \mathrm{C}$ until analysis. [Pancreas 1 was obtained from a 40 year old male road traffic accident victim and pancreas 2 was from a 60 year old female who had suffered a subarachnoid hemorrhage.] These tissues $(3 \times$ ca. $50 \mathrm{mg}$ lots of each) were solubilized in dilute aqueous TFA $(0.1 \% ; 1 \mathrm{~mL})$ with the addition of porcine insulin $(2.5 \mathrm{nmol})$ as the internal standard. The extracts were passed through preconditioned C18 Sep-Pak cartridges, washed with aqueous TFA $(0.1 \% ; 5 \mathrm{~mL})$, and the insulin was eluted in $\mathrm{CH}_{3} \mathrm{CN}: \mathrm{H}_{2} \mathrm{O}$ :TFA $(80: 20: 0.1 ; 1 \mathrm{~mL})$. Eluents were evaporated under reduced pressure to yield aliquots of ca. $50 \mu \mathrm{L}$. These were mixed and diluted 1:20 in sinapinic acid matrix solution and $1 \mu \mathrm{L}$ aliquots applied to the MALDI target. Standard solutions containing human insulin $(0,40,120,400,1200,2800,4000$ pmol) and porcine insulin (200 pmol) were prepared in aqueous TFA $(0.1 \%$; $20 \mu \mathrm{L}$; containing $5 \mathrm{nmol} / \mathrm{mL}$ BSA).

ANALYSIS OF HEMORPHINS AND CATECHOLAMINES IN HUMAN ADRENAL AND PHEOCHROMOCYTOMA TISSUE. Hemorphins. Extracts of control adrenal glands $(n=10)$ and surgically removed, histologically verified pheochromocytoma $(n=3)$ had previously been prepared as described above, but with the addition of protease inhibitors. Hemorphin content was determined by electrospray MS at that time [49]. The extracts were then stored at $-20^{\circ} \mathrm{C}$ until the present study. These same extracts were thawed, mixed with rat LVV-hemorphin-7 (300 pmol/mg tissue, internal standard), diluted 1:30 with 4HCCA solution and then analyzed by MALDI-TOFMS.

A single tissue extract, previously found to have the lowest LVV-hemorphin-7 concentration, was employed as the sample matrix for the preparation of a standard addition calibration curve. Aliquots of this sample were spiked with human LVV-hemorphin-7 (0, 10, 30, 60, 100,300 , and $600 \mathrm{pmol} / \mathrm{mg}$ tissue) and a fixed amount of rat LVV-hemorphin-7 (300 pmol/mg tissue).

Control samples $(n=3)$ were also included in the analysis. These were prepared from each of the pheochromocytoma extracts by adding internal standard and spiking with human LVV-hemorphin-7 (100 $\mathrm{pmol} / \mathrm{mg}$ tissue).

Catecholamines. Frozen tissue samples $\left(-70^{\circ} \mathrm{C}\right.$; ca. $100 \mathrm{mg}$ each) from control adrenal glands $(\mathrm{n}=3)$ and histologically verified pheochromocytoma $(n=3)$ were extracted into aqueous TFA $(0.1 \%, 1 \mathrm{~mL})$ as previously described.

Aliquots $(10 \mu \mathrm{L})$ from each tissue extract were mixed with the internal standards (i.e., $\left[{ }^{2} \mathrm{H}_{3}\right]$-epinephrine $\{2$ nmol $\}$ and $\left[{ }^{2} \mathrm{H}_{3}\right]$-norepinephrine $\left.\{3 \mathrm{nmol}\}\right)$. The samples were then diluted 1:25 in ferulic acid matrix solution, mixed, cooled to $4{ }^{\circ} \mathrm{C}$ for $10 \mathrm{~min}$ and centrifuged $(14,000$ $\mathrm{g}$, $10 \mathrm{~min}$.) to precipitate protein. Aliquots $(0.25 \mu \mathrm{L})$ of the supernatant were loaded directly on the MALDI target for analysis.
An extract of surgically resected adrenal cortex was employed as the sample matrix for the preparation of a standard addition calibration curve. Aliquots of this sample, each corresponding to $5 \mathrm{mg}$ of tissue, were spiked with $0,0.5,1.5,3,5,15,30,45,60$, and 90 nmol of both epinephrine and norepinephrine, together with fixed amounts of the internal standards $\left(\left[{ }^{2} \mathrm{H}_{3}\right]\right.$-epinephrine $\{20 \mathrm{nmol}\}$ and $\left[{ }^{2} \mathrm{H}_{3}\right]$-norepinephrine $\left.\{30 \mathrm{nmol}\}\right)$. These spiked extracts were diluted 1:25 in ferulic acid solution prior to analysis.

ANALYSIS OF HOMOVANILLIC ACID IN HUMAN URINE SAMPLES. Urine samples were collected from 19 healthy volunteers and adjusted to $\mathrm{pH} 2.5$. The internal standard, $\left[{ }^{2} \mathrm{H}_{5}\right]-\mathrm{HVA}(100 \mathrm{nmol})$ was added to aliquots of each sample $(50 \mu \mathrm{L})$ and the mixture was extracted into ethyl acetate (four volumes, three times). Extracts were combined, taken to dryness under reduced pressure and the residue reconstituted in dilute $\mathrm{HCl}(0.1 \mathrm{M}$, $50 \mu \mathrm{L})$. Samples were diluted 1:10 in DHB matrix solution and were then spotted on to the MALDI target. Each urine sample was also independently analyzed for HVA content at a commercial clinical chemistry laboratory.

Standard solutions containing $\operatorname{HVA}(0,25,50,100$, 500 , and $1000 \mathrm{pmol})$ and $\left[{ }^{2} \mathrm{H}_{5}\right]$-HVA (100 pmol) were prepared in water and diluted 1:5 in DHB matrix solution prior to analysis (final volume $20 \mu \mathrm{L}$ ).

\section{Mass Spectrometry}

Equipment. A Perseptive Voyager DE STR MALDI time-of-flight mass spectrometer (Perseptive Biosystems, Framingham, MA), equipped with a Tektronix TDS 540C digital oscilloscope (500 MHz, digitization rate 2 Gigasamples/s) was used for all mass spectrometry. The instrument was used in both positive ion linear (LDE) and reflector (RDE) modes with delayed extraction.

Data acquisition parameters. Samples were run in the autosampler mode and the laser was operated at a fixed fluence that was manually optimized for each sample set. Optimization involved obtaining peaks with the highest possible signal to noise ratio without significant peak broadening. Laser firing patterns started at the center of each sample spot and spiraled progressively outwards to a notional spot perimeter. The laser fired between 1 and 16 times at each location in the firing pattern. For each sample spot, spectra meeting acceptance criteria (i.e., minimum and maximum peak intensity thresholds) obtained from 256 laser shots were averaged to form a single spectrum. The parameters used for the analysis of each sample are summarized in Table 1 . Between 10 and 20 sample spots were analyzed for each standard solution and biological sample.

For the hemorphin assay, the instrument was programmed to fire multiple laser shots at a single point on the sample spot, averaging the intensity of the compos- 
Table 1. Acceptance criteria used for each sample

\begin{tabular}{|c|c|c|c|c|c|c|c|c|}
\hline & $\begin{array}{c}\text { LDE } \\
\text { growth } \\
\text { hormone }\end{array}$ & $\begin{array}{l}\text { LDE insulin } \\
\text { standard } \\
\text { curve }\end{array}$ & $\begin{array}{l}\text { LDE } \\
\text { pancreatic } \\
\text { extracts } \\
\text { (insulin) }\end{array}$ & $\begin{array}{l}\text { RDE insulin } \\
\text { standard } \\
\text { curve }\end{array}$ & $\begin{array}{c}\mathrm{RDE} \\
\text { pancreatic } \\
\text { extracts } \\
\text { (insulin) }\end{array}$ & $\begin{array}{l}\text { LDE } \\
\text { hemorphins }\end{array}$ & $\begin{array}{c}\mathrm{RDE} \\
\text { catecholamine }\end{array}$ & $\begin{array}{c}\text { RDE } \\
\text { homovanillic } \\
\text { acid }\end{array}$ \\
\hline Minimum intensity & 3,500 & 0 & 4,000 & 0 & 6,000 & 1,500 & 1,500 & 5,000 \\
\hline Maximum intensity & 62,000 & 63,000 & 20,000 & 63,000 & 63,000 & 15,000 & 15,000 & 63,000 \\
\hline Positions in search pattern & 500 & 500 & 203 & 500 & 203 & 26 & 81 & 500 \\
\hline Laser shots per position & 1 & 1 & 16 & 1 & 12 & 8 & 12 & 1 \\
\hline
\end{tabular}

ite spectrum in the digitizer, before downloading it to the computer. The computer compared the spectrum with user-defined minimum and maximum absolute intensity criteria, and then either accepted or rejected each spectrum. If the full range of signal intensities is acquired, individual spectra with high ion intensities for either the analyte or internal standard can dominate averaged peak ratio statistics in the final spectrum. To minimize this problem, the hemorphin data were acquired using a small number of laser shots per position (eight shots) with the maximum intensity set to approximately one quarter of the saturation limit. This approach reduced the available instrument dynamic range, but kept analysis times reasonably short ( 3 to 6 min per sample spot). Because we were only interested in calibration over a dynamic range of two orders of magnitude, this approach did not compromise the study.

An alternative approach, used for the HVA assay, excludes saturated data from the final spectrum and allows the instrument's full dynamic range to be utilized. Data from individual laser shots are downloaded from the digitizer and signal intensity compared with a user-defined maximum intensity threshold set just below the saturation limit. This approach completely eliminates saturated data without compromising the dynamic range.

\section{Mass calibration}

GROWTH HORMONE. Spectra were externally mass calibrated on the singly and doubly charged molecular species of $\beta$-lactoglobulin $\left([\mathrm{M}+\mathrm{H}]^{+}=18,364.4 \mathrm{Da}\right.$ and $\left.[\mathrm{M}+2 \mathrm{H}]^{2+}=9182.7 \mathrm{Da}\right)$.

INSULIN. Insulin spectra acquired in LDE mode were externally calibrated on the (average) mass of the singly protonated molecule of porcine insulin ([M + $\left.\mathrm{H}^{+}=5778.7 \mathrm{Da}\right)$. Each spectrum acquired in RDE mode was internally calibrated to correctly identify the monoisotopic species in each insulin peak cluster. Each mass spectrum was heavily smoothed (Savitsky-Golay, second order polynomial, 150 points) to produce a single peak for porcine insulin. The centroid of this peak $\left([\mathrm{M}+\mathrm{H}]^{+}=5778.7 \mathrm{Da}\right)$ was used to calibrate the original isotopically resolved data.

HEMORPHINS. The mass spectrometer was externally calibrated using the monoisotopic protonated molecular ion of substance $\mathrm{P}\left([\mathrm{M}+\mathrm{H}]^{+}=1347.7 \mathrm{Da}\right)$. All data were acquired in LDE mode.

CATECHOLAMINES AND HOMOVANILLIC ACID. Catecholamine and HVA data were acquired in RDE mode at reduced accelerating voltage $(7 \mathrm{kV})$. For the catecholamines, each spectrum was internally calibrated on the protonated molecules of $\left[{ }^{2} \mathrm{H}_{3}\right]$-epinephrine $\left([\mathrm{M}+\mathrm{H}]^{+}=187.1162\right)$ and $\left[{ }^{2} \mathrm{H}_{3}\right]$-norepinephrine $([\mathrm{M}+$ $\left.\mathrm{H}^{+}=173.1005\right)$. For homovanillic acid, spectra were internally mass calibrated on the molecular ion of $\left[{ }^{2} \mathrm{H}_{5}\right]$-HVA $\left(\mathrm{M}^{+}=187.0893 \mathrm{Da}\right)$ and the singly protonated molecule of DHB $\left(\mathrm{M}^{+}=154.0266 \mathrm{Da}\right)$.

Data processing and calibration curves. Individual spectra were obtained for the analysis of each sample spot and the heights of the relevant peaks were determined. The analyte to internal standard peak height ratio was calculated for each spectrum and then the mean value and standard deviation were determined for each sample and standard. For homovanillic acid, peak area ratios of analyte/internal standard were also determined to construct a calibration curve and to determine its concentration in urine.

Calibration curves were constructed by plotting mean values for the observed signal intensity ratio against the nominal molar ratio. The calibration curves were used to determine the concentration of each analyte in its respective biological matrix.

The RDE data obtained for insulin were processed in a specific manner. The peak heights of the first eight isotopes of human insulin (5804.7 to $5811.7 \mathrm{Da})$ were recorded and summed. Similarly, the peak heights of the corresponding ions ( 5774.7 to $5781.7 \mathrm{Da}$ ) in the porcine insulin isotope cluster were recorded and summed. The calibration curve was obtained by plotting the ratio of summed analyte peak heights to summed internal standard peak heights against their nominal molar ratio.

\section{Results and Discussion}

\section{Analysis of Growth Hormone in Rat Pituitary Tissue}

Growth hormone in rat pituitary tissue $(n=2)$ was successfully quantified using $\beta$-lactoglobulin as the internal standard. Figure 1 shows a MALDI mass spectrum of rat pituitary extract spiked with $\beta$-lactoglobulin 


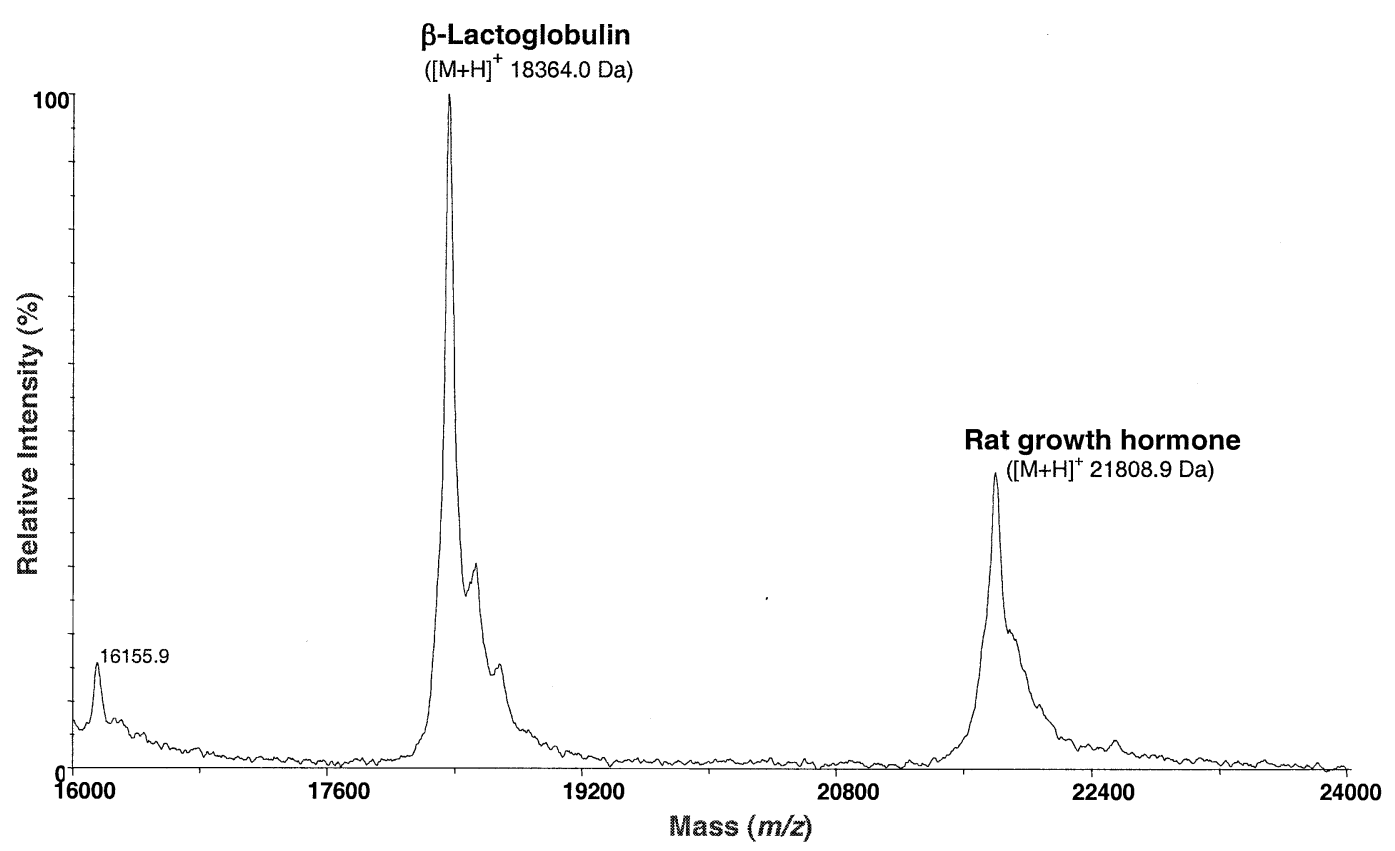

Figure 1. A representative MALDI mass spectrum for growth hormone $\left([\mathrm{M}+\mathrm{H}]^{+} 21,808 \mathrm{Da}\right)$ in a rat pituitary extract. $\beta$-Lactoglobulin $\left(15 \mathrm{nmol},[\mathrm{M}+\mathrm{H}]^{+} 18,364 \mathrm{Da}\right)$ was added as an internal standard and caffeic acid was used as the MALDI matrix.

$\left(15 \mathrm{nmol} ;\left([\mathrm{M}+\mathrm{H}]^{+}=18,364.4 \mathrm{Da}\right)\right.$ with caffeic acid as the matrix and run in LDE mode. The amount of internal standard applied to the target was 5 pmoles. The peak height ratio was calculated, and then converted to a molar ratio by reference to the calibration curve. At higher mass, the doubly charged species for these proteins, as well as other minor protein components from the pituitary gland. Figure 2 shows the calibration curve obtained for rat methionyl growth hormone $\left([\mathrm{M}+\mathrm{H}]^{+}=21,812.1 \mathrm{Da}\right)$ without correction based on the internal standard ( $\beta$-lactoglobulin). The curve was constructed by plotting the average signal

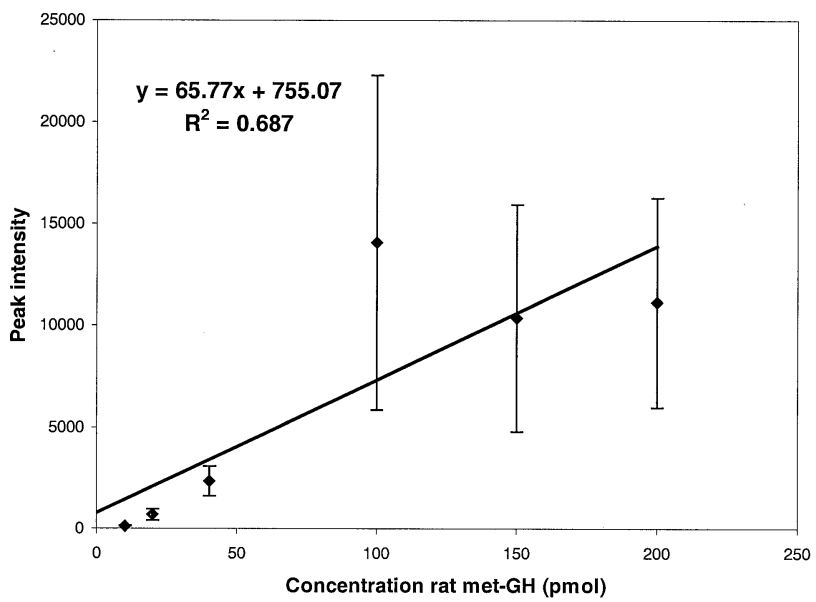

Figure 2. A representative standard curve obtained for methionyl rat growth hormone (met-rGH, 0-200 pmol) without an internal standard. The plot is the average peak height ratios for met-rGH (y-axis) plotted against amount (x-axis) applied to the MALDI target. Error bars represent standard deviations. intensity for 10 determinations (y-axis) against the amount of methionyl growth hormone applied to the MALDI target (x-axis). Figure 3 shows the calibration curve obtained for rat methionyl growth hormone corrected with $\beta$-lactoglobulin, the internal standard. In this case, peak height ratios of analyte to internal standard were used to construct the calibration curve. Plotting the ratio of analyte/internal standard markedly increased the precision, but it is important to note that the internal standard has no sequence homology

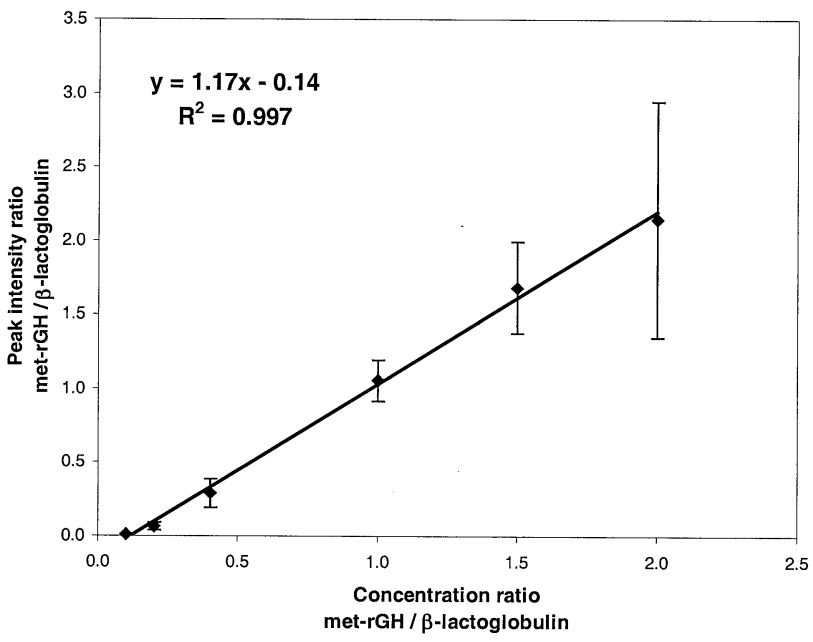

Figure 3. A representative standard curve obtained for methionyl rat growth hormone (met-rGH, $0-200$ pmol) using $\beta$-lactoglobulin $(100 \mathrm{pmol})$ as the internal standard. The plot is the average peak height ratios for met-rGH to $\beta$-lactoglobulin $(\mathrm{n}=10)$ plotted against molar concentration ratio. Error bars represent standard deviation. 
HUMAN INSULIN A CHAIN

PORCINE INSULIN A CHAIN

\section{HUMAN INSULIN B CHAIN}

PORCINE INSULIN B CHAIN
Amino acid sequence

GIVEQCCTSICSLYQLENYCN

GIVEQCCTSICSLYQLENYCN

Figure 4. The amino acid sequence for human and porcine insulin. Insulin is composed of two subunits joined by two intramolecular disulfide bonds. Insulin A chain consists of 21 amino acids and insulin B chain consists of 30 amino acids. Shown are the amino acid sequences for porcine and human insulin A and B chains. The sequences for these polypeptides differ by one amino acid (highlighted).

with the analyte in this specific example. This is less than ideal, but a comparision of Figures 2 and 3 indicates that the internal standard still serves a useful function and enhances precision. The corrected calibration curve is linear $\left(\mathrm{R}^{2}=0.997\right.$, slope $\left.=1.17\right)$ over the relative analyte/internal standard concentration range 0.1 to $2.0(1-21 \mu \mathrm{mol} / \mathrm{g}$ tissue or $0-200 \mathrm{pmol}$ met-GH), but has a non-zero intercept. The deviation of the data from the line of best fit at higher molar ratios is likely a consequence of the compromise with internal standard selection. (See the results for the quantification of insulin that follow.)

The concentrations of rGH in 2 rat pituitary glands were determined $(2.40 \pm 0.23$ and $2.49 \pm 0.25 \mu \mathrm{mol} / \mathrm{g}$ tissue; mean $\pm \mathrm{SD})$. These values fall within the published concentration range for $\mathrm{rGH}$ in rat pituitary gland [50]. Coefficients of variation for rGH determinations in rat pituitary extracts were below $20 \%(n=10)$.

\section{Analysis of Insulin in Human Pancreatic Tissue}

Spectra showing baseline resolved (single) peaks for human $\left([\mathrm{M}+\mathrm{H}]^{+}=5808.7 \mathrm{Da}\right)$ and porcine insulin $\left([\mathrm{M}+\mathrm{H}]^{+}=5778.7 \mathrm{Da}\right)$ were obtained in LDE mode. Spectra obtained in RDE mode showed isotopically resolved peak clusters for each peptide. (Figure 4 shows the sequences for both human and porcine insulins; Figures $5 a$ and $b$ the spectra obtained in LDE and RDE mode). Calibration curves were obtained for insulin in both LDE $\left(\mathrm{R}^{2}=0.999\right.$, slope $\left.=1.08\right)$ and $\operatorname{RDE}\left(\mathrm{R}^{2}=\right.$ 0.999 , slope $=0.98$ ) modes (Figure 6) over the analyte/ internal standard relative concentration range 0.06 to 3.0 (equivalent to $3-150 \mathrm{nmol} / \mathrm{g}$ tissue). The results from analysis of multiple sections of two pancreatic tissues are shown in Table 2. Insulin concentrations measured in the two modes were comparable; however, coefficients of variation for the LDE determinations were considerably better than those generated in RDE mode, consistent with the significantly higher absolute peak intensity and signal-to-noise ratio observed in the LDE spectra.

\section{Quantification of Hemorphins in Human Adrenal and Pheochromocytoma Tissue}

Spectra showing isotopically resolved peaks for human LVV-hemorphin-7 (monoisotopic $[\mathrm{M}+\mathrm{H}]^{+}=1308.7$ Da) and rat LVV-hemorphin-7 (monoisotopic [M + $\mathrm{H}^{+}=1324.7 \mathrm{Da}$ ) were obtained. A standard addition curve in an adrenal extract was constructed and was linear $\left(\mathrm{R}^{2}=0.999\right)$ over the analyte added/internal standard relative concentration range 0.03 to 2.0 (7 to $500 \mathrm{nmol} / \mathrm{g}$ tissue). Control samples were prepared from the pheochromocytoma samples by spiking them
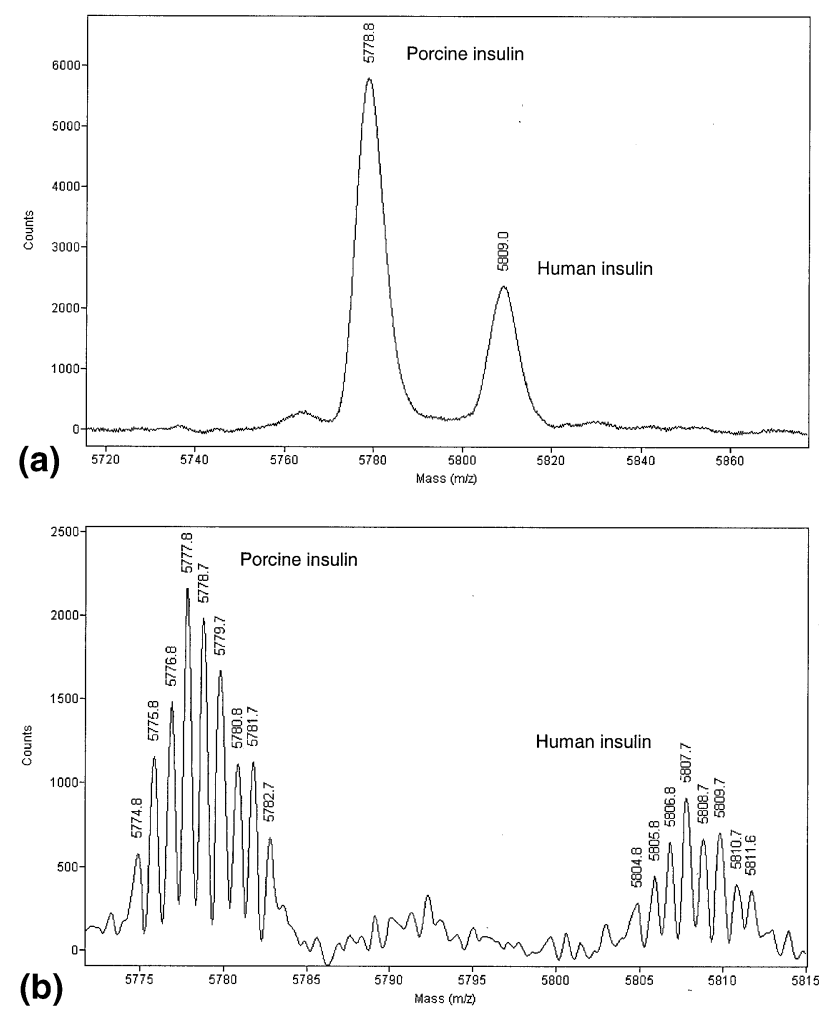

Figure 5. Mass spectra showing human insulin (400 pmol) and porcine insulin (internal standard, $200 \mathrm{pmol}$ ) acquired in (a) LDE mode and (b) RDE mode. 

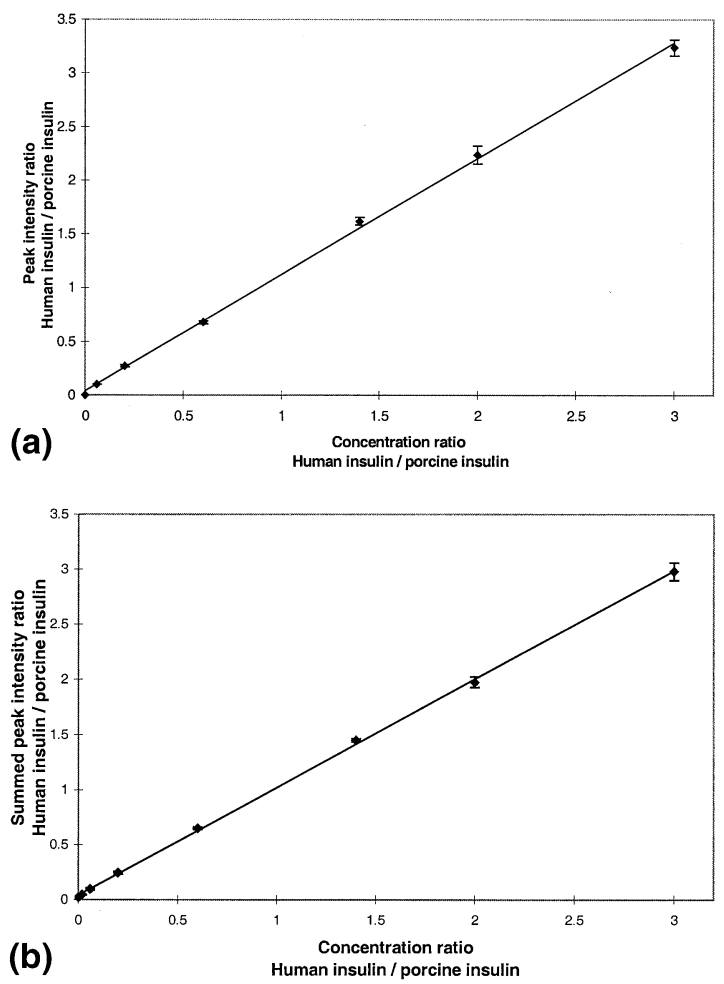

Figure 6. Linear calibration curves for human insulin, using porcine insulin as internal standard. Calibration curves were acquired in $(\mathbf{a})$ LDE mode $\left(R^{2}=0.999\right.$, slope $\left.=1.082\right)$ and $(\mathbf{b}) \mathrm{RDE}$ mode $\left(R^{2}>0.999\right.$, slope $\left.=0.981\right)$. The signal intensity ratio is the ratio of the summed peak heights of the first 8 isotopes of human insulin $\left([\mathrm{M}+\mathrm{H}]^{+}=5804.7\right.$ to $\left.5811.7 \mathrm{Da}\right)$ to that of the first eight isotopes of porcine insulin $\left([\mathrm{M}+\mathrm{H}]^{+}=5774.7\right.$ to $\left.5781.7 \mathrm{Da}\right)$.

with human LVV-hemorphin-7 (100 nmol/g tissue). The control samples yielded values that were $124 \pm 14$, $112 \pm 16$, and $100 \pm 6 \mathrm{nmol} / \mathrm{g}$ higher than the corresponding pheochromocytoma samples, consistent with the amount spiked into each.

The results obtained for the MALDI analysis of 10 adrenal tissues and 3 pheochromocytoma samples are compared with results obtained from a previous electrospray MS analysis of the same extracts in Figure 7 [49]. The concentrations obtained by MALDI-TOFMS

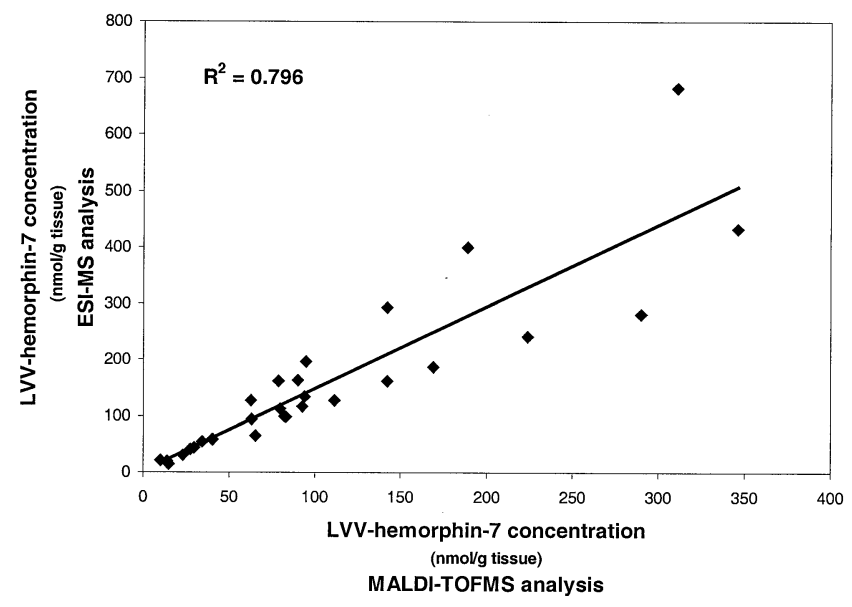

Figure 7. A comparison of LVV-hemorphin-7 concentrations in human adrenal gland determined by MALDI-TOFMS and ESI-MS. The values obtained by MALDI-TOFMS are the average of 10 separate determinations. Coefficients of variation (CV) for each measurement were less than $10 \%$.

are either lower or virtually identical to those obtained previously. We note that the electrospray MS assay was based on measurement of absolute analyte signal intensity without inclusion of an internal standard, and thereafter, the extracts were stored for ca. two years at $-20^{\circ} \mathrm{C}$ before the MALDI-TOFMS data were acquired. It is reasonable to assume that some proteolysis occurred in those samples with lower analyte concentrations. Degradation likely arose during the repeat freezethaw cycles.

\section{Quantification of Low Molecular Weight Analytes}

Catecholamines in human adrenal tissue. A spectrum showing peaks for norepinephrine $\left([\mathrm{M}+\mathrm{H}]^{+}=\right.$ $170.0817 \mathrm{Da}), \quad\left[{ }^{2} \mathrm{H}_{3}\right]$-norepinephrine $\left([\mathrm{M}+\mathrm{H}]^{+}=\right.$ 173.1005 Da), epinephrine $\left([\mathrm{M}+\mathrm{H}]^{+}=184.0974 \mathrm{Da}\right)$, and $\left[{ }^{2} \mathrm{H}_{3}\right]$-epinephrine $\left([\mathrm{M}+\mathrm{H}]^{+}=187.1161 \mathrm{Da}\right)$ was obtained in RDE mode (Figure 8). Instrument parameters were optimized to provide the highest possible resolution. Standard addition curves for both analytes,

Table 2. Insulin concentrations in human pancreatic tissue. Insulin determinations for sections A, B and C of pancreas tissues 1 and 2

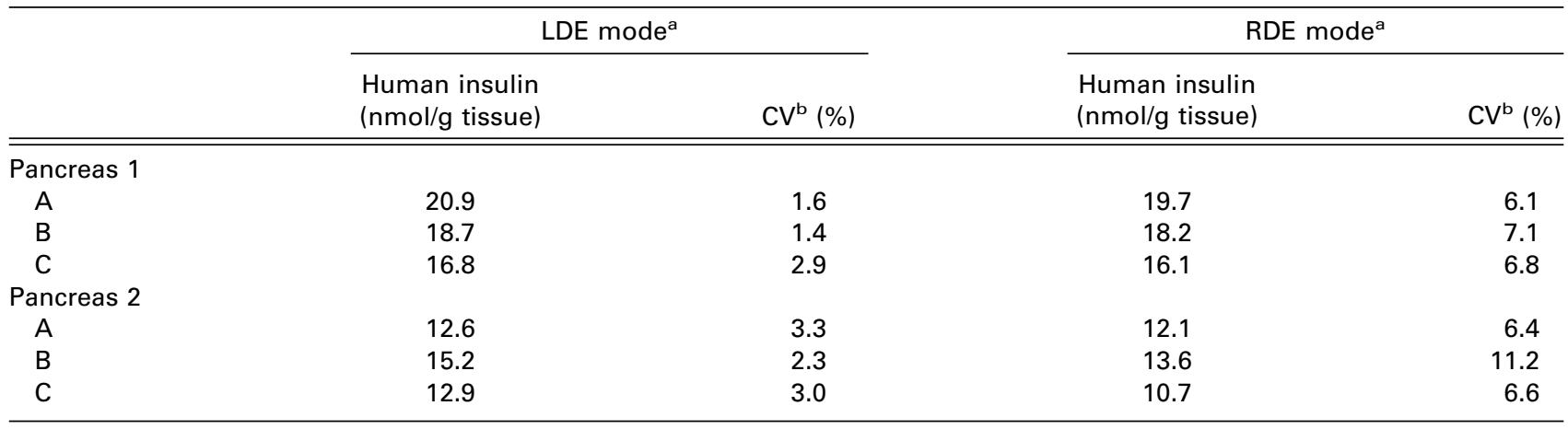

aSamples were assayed in both LDE and RDE modes and values reported are the average of 10 determinations ${ }^{\mathrm{b}} \mathrm{CV}$ is the standard deviation expressed as the percentage of the mean $(\mathrm{CV}=\sigma / \mu)$ 


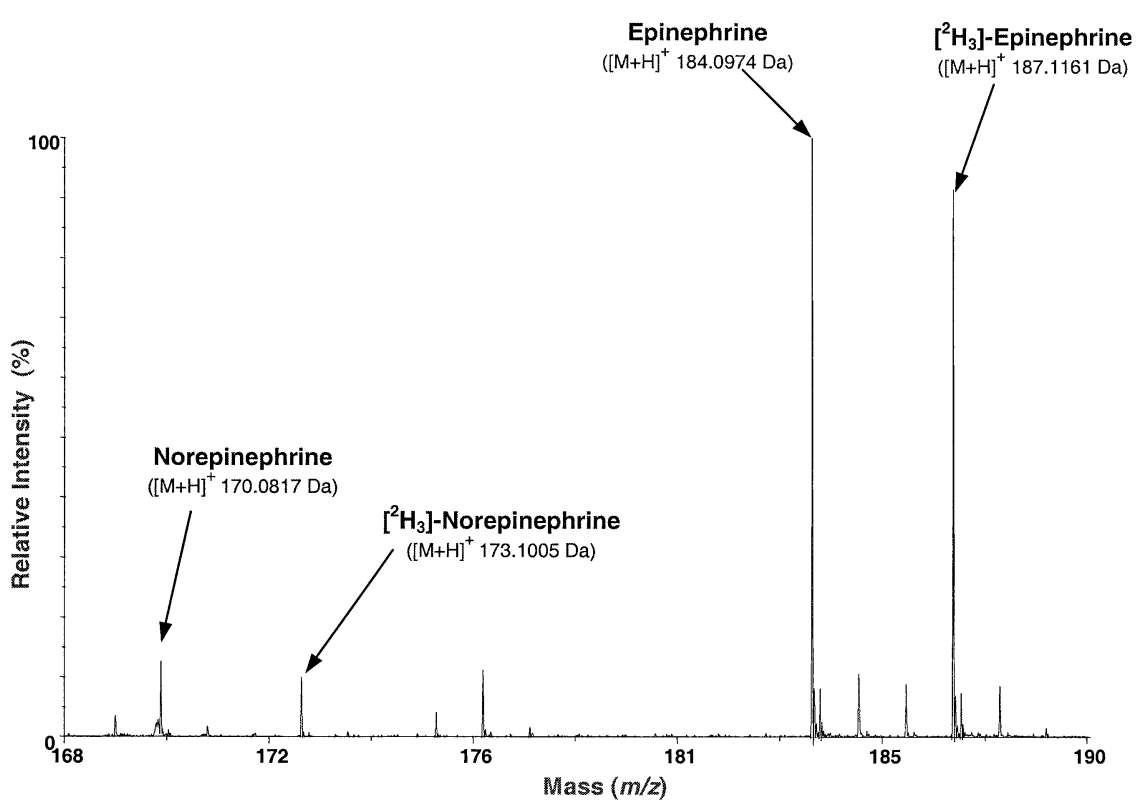

Figure 8. A representative MALDI-TOF mass spectrum for norepinephrine $\left([\mathrm{M}+\mathrm{H}]^{+}=170.0817\right.$ Da) and epinephrine $\left([\mathrm{M}+\mathrm{H}]^{+}=184.0974 \mathrm{Da}\right)$ and their respective internal standards $\left[{ }^{2} \mathrm{H}_{3}\right]-$ norepinephrine $\left([\mathrm{M}+\mathrm{H}]^{+}=173.1005 \mathrm{Da}\right),\left[^{2} \mathrm{H}_{3}\right]$-epinephrine $\left([\mathrm{M}+\mathrm{H}]^{+}=187.1162 \mathrm{Da}\right)$ in human adrenal extracts. The spectrum was acquired in RDE mode.

prepared in an extract of surgically resected adrenal cortex, were assayed in ferulic acid matrix. The curves were linear over the analyte added/internal standard relative concentration ranges 0.02 to 2.0 for norepinephrine $\left(R^{2}=0.998\right)$ and 0.025 to 4.5 for epinephrine $\left(R^{2}=\right.$ 0.999).

Table 3 shows the results for the analysis of three sections of whole adrenal tissue and 3 pheochromocytoma samples. Initially, norepinephrine analyte/internal standard peak height ratios for the pheochromocytoma samples were higher than those obtained for the highest standard in the calibration curve. The extracts for these samples were reanalyzed using a higher concentration ( $3 \mathrm{nmol} / \mu \mathrm{L}$ extract) of the internal standard.

The catecholamine spectrum shown in Figure 8 illustrates the additional specificity available in RDE mode for low molecular weight analytes. This is important because in several samples, the signal for norepineph- rine $\left([\mathrm{M}+\mathrm{H}]^{+}=170.0817 \mathrm{Da}\right)$ was not the most intense at the nominal mass value of $170 \mathrm{Da}$. It was only possible to accurately quantify norepinephrine in the adrenal tissue extracts because its signal could be completely resolved from other peaks of the same nominal mass. When spectra were internally calibrated, mass assignments for both catecholamines were accurate to better than $5 \mathrm{ppm}$. This limits possible elemental compositions to a unique formula, or just a few alternatives.

Homovanillic acid in human urine. Spectra showing signals for the protonated molecule of HVA $\left(\mathrm{M}^{+}=\right.$ 182.0579 Da) and $\left[{ }^{2} \mathrm{H}_{5}\right]$-HVA $\left(\mathrm{M}^{+}=187.0893 \mathrm{Da}\right)$ were obtained in RDE mode. Linear calibration curves were constructed for the analyte/internal standard relative concentration range 0 to 10 using either peak height ratios or peak area ratios (peak height ratios: $R^{2}=0.999$, slope $=0.972$; peak area ratios: $R^{2}=0.999$, slope $=$ 1.055). (The spectra were of comparable resolution and

Table 3. Catecholamine concentrations in human adrenal gland

\begin{tabular}{lcccc}
\hline & \multicolumn{2}{c}{ Norepinephrine } & \multicolumn{2}{c}{ Epinephrine } \\
\cline { 2 - 3 } Sample & $\begin{array}{c}\text { Mean value } \\
\text { (nmol/g tissue) }\end{array}$ & CV (\%) & $\begin{array}{c}\text { Mean value } \\
\text { (nmol/g tissue) }\end{array}$ \\
\hline \hline Adrenal gland A & 233 & 16 & 279 & 6 \\
Adrenal gland B & 510 & 13 & 582 & 10 \\
Adrenal gland C & 499 & 17 & 690 & 184 \\
Pheochromocytoma 1 & 3,989 & 7 & 2,854 & 8 \\
Pheochromocytoma 2 & 6,708 & 8 & 5,735 & 4 \\
Pheochromocytoma 3 & 59,940 & 5 & & 19 \\
\hline
\end{tabular}

${ }^{a}$ The norepinephrine data for all pheochromocytoma samples were obtained using higher concentrations of the internal standards $\left(\left[{ }^{2} \mathrm{H}_{3}\right]-\right.$ norepinephrine, i.e., $3 \mathrm{nmol} / \mu \mathrm{L}$ extracts). 


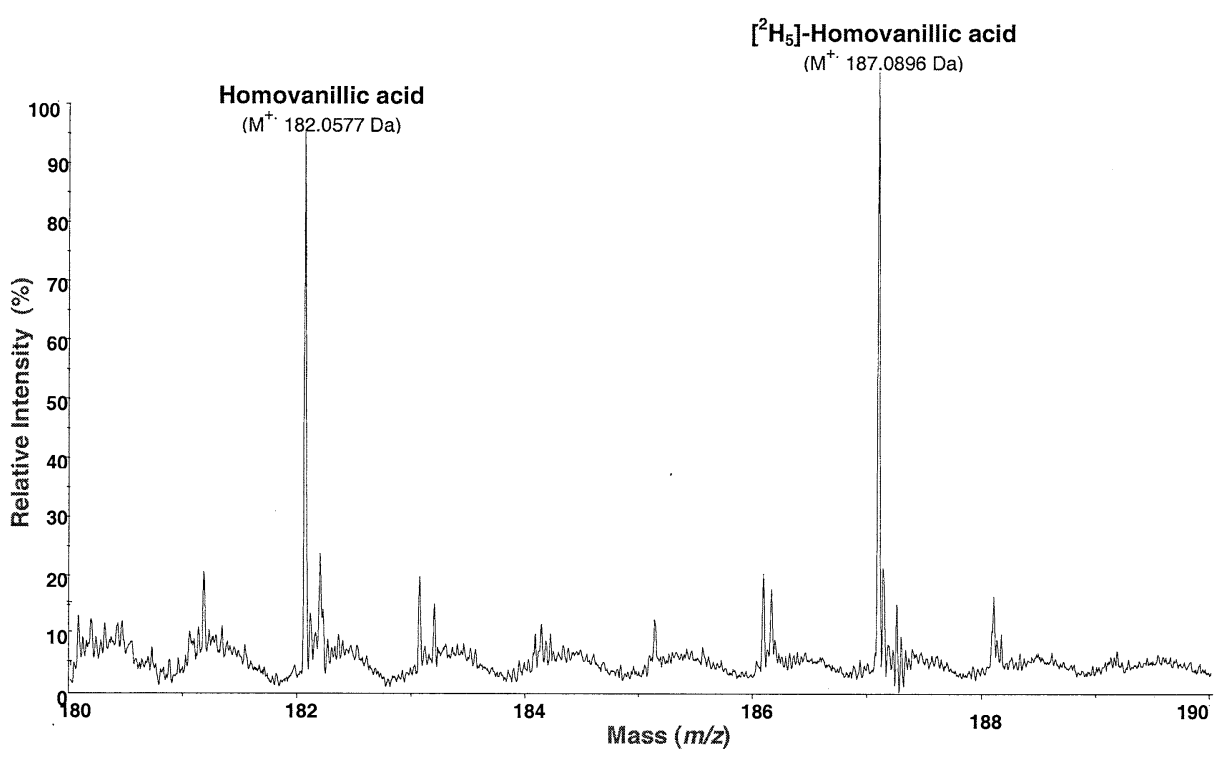

Figure 9. A representative MALDI mass spectrum for homovanillic acid detected in human urine. The internal standard $\left[{ }^{2} \mathrm{H}_{5}\right]$-homovanillic acid $(100 \mathrm{pmol})$ was added prior to analysis. Samples were analyzed in reflector mode using 2,5-dihydroxybenzoic acid as the MALDI matrix.

mass accuracy to those obtained for epinephrine and norepinephrine in tissue extracts.)

Homovanillic acid in urine was quantified using DHB as the MALDI matrix, with coefficients of variation typically less than $20 \%$. A representative mass spectrum across the appropriate mass range is included as Figure 9. The same urine samples were also independently analyzed for homovanillic acid, and these results were comparable to those obtained by MALDI-TOFMS. Figure 10 compares the homovanillic acid values measured by a commercial clinical chemistry laboratory (HPLC analysis) with those obtained by both peak height (Figure 10a) and peak area ratios (Figure 10b). Similar correlation coefficients were obtained for both approaches (0.915 and 0.942 respectively).

Figure 11 shows the coefficients of variation (y-axis) for the measured peak height ratios of homovanillic acid $/\left[{ }^{2} \mathrm{H}_{5}\right]$-homovanillic (equimolar ratios in DHB) when different number of laser shots is varied.

\section{Conclusion}

Our aim was to examine the utility of MALDI-TOFMS for the quantification of endogeneous levels of a wide range of biomolecules in complex biological matrices. Rather than exhaustively explore limits of detection, limits of quantification, linearity, precision and accuracy, we have simply selected a few example problems to demonstrate that automated MALDI-TOFMS can deliver good quantitative data for a wide range of compounds in various complex biological matrices. Linear calibration curves with $\mathrm{R}^{2}>0.99$ were routinely constructed for analytes ranging in molecular weight from 170 to $22 \mathrm{kDa}$. Analytes were quantified in crude tissue extracts and urine with either similar compounds
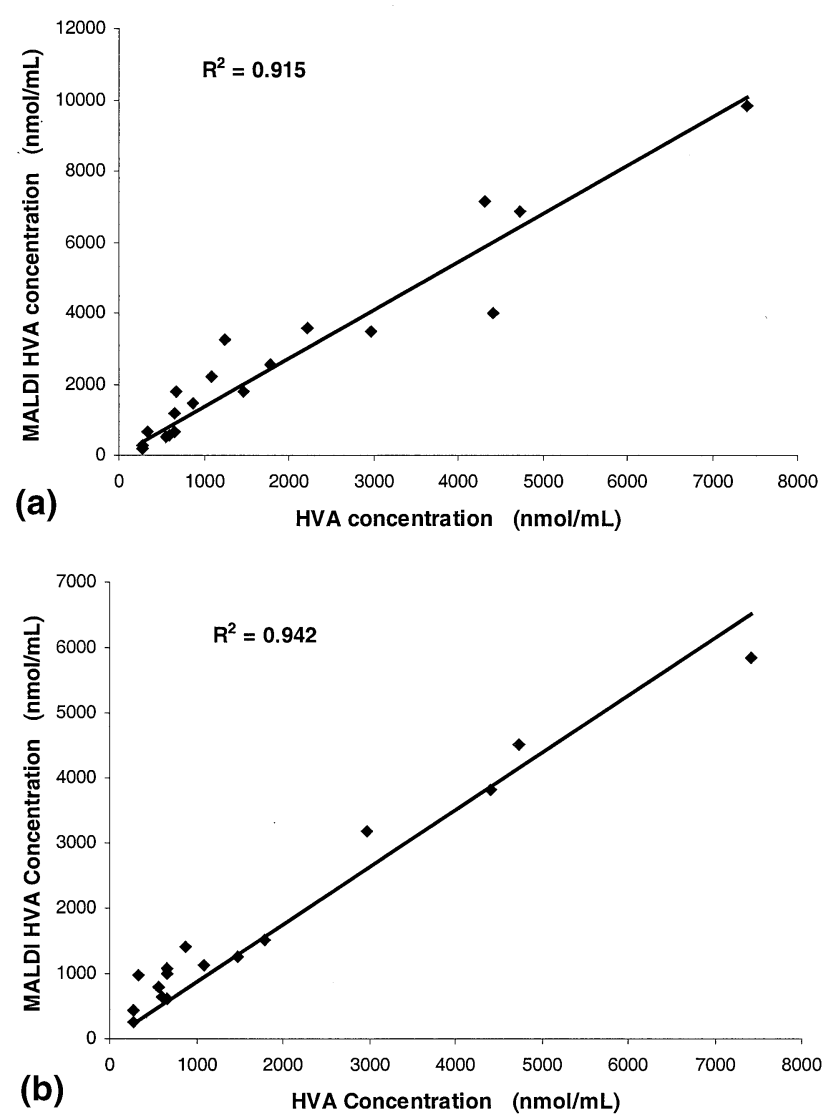

Figure 10. The values obtained for HVA in random urine samples $(\mathrm{n}=19)$ by MALDI-TOFMS calculated using (a) peak height ratios and (b) peak area ratios were comparable with the concentration measured using an independent established method. The coefficient of variation for each urine sample, when analyzed by MALDI-TOFMS, was less than $20 \%$. 


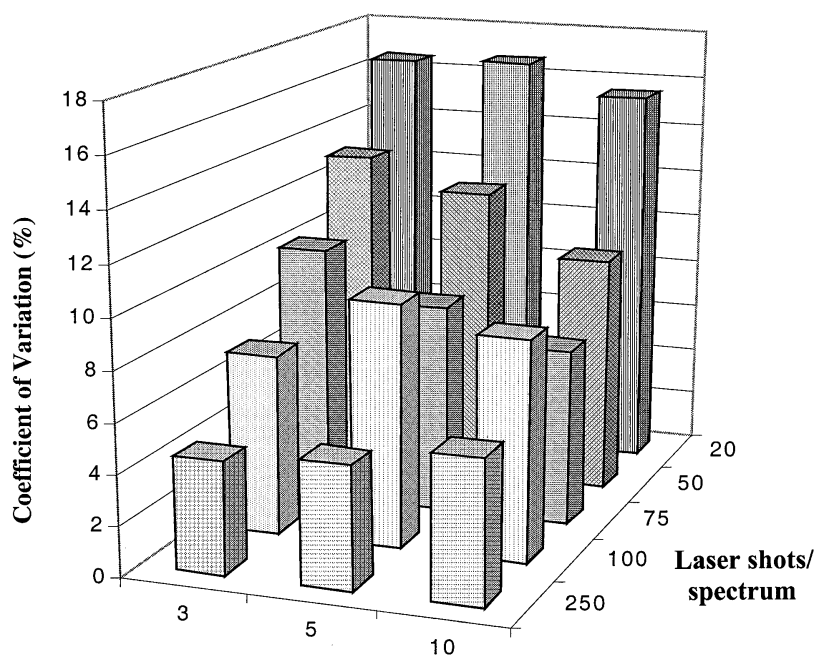

Number of Sample Positions

Figure 11. Shown are the coefficients of variation (y-axis) for the measured peak height ratios of homovanillic acid $/\left[{ }^{2} \mathrm{H}_{5}\right]$-homovanillic (equimolar ratios in DHB) when different number of laser shots are acquired per spectrum (z-axis) and averaged across a number of different target positions (x-axis).

of comparable molecular weight, structural analogs, or isotopomers incorporated as internal standards.

A high degree of specificity was achieved using RDE analysis for the catecholamine and HVA assays. The mass resolution achieved in these assays allowed measurement of specific analytes in the presence of contaminants of the same nominal mass and mass assignments accurate to $5 \mathrm{ppm}$ were possible. An assay dynamic range of $\sim 2.5$ orders of magnitude was readily achievable. Some instrument dynamic range and signal saturation problems were observed, but solutions or workarounds for these were found and evaluated.

\section{Precision}

One of the most important objectives of method development was to maximize assay precision whilst retaining reasonable analysis times. In this study we determined that at least 75 laser shots from three target positions are required to achieve reproducible ratios and optimal precision (see Figure 11). In practice we generally acquired the maximum number of shots (256) permitted by the instrument software and incorporated signals from at least 10 firing positions. Precision generally improved with absolute peak intensity, and coefficients of variation were below $20 \%$ for all assays in this study.

During method development we examined peak height ratio variation between different firing positions within a sample spot, and between successive multishot composite spectra acquired at the same firing position (data not shown). For a given matrix and sample combination, the variations were very similar, regardless of whether the firing position changed between acquisitions. This is consistent with the three- dimensional variation in the pattern of analyte-matrix co-crystallization. We also noted that the variation was greater for tissue extracts than for pure standards, which supports the notion that variation is inherently related to the cocrystallization process.

\section{Accuracy}

The accuracy of quantitative MALDI-TOFMS has been demonstrated across an extended mass range. The values determined here for $\mathrm{rGH}(2.40$ and $2.49 \mu \mathrm{mol} / \mathrm{g}$ tissue) in rat pituitary tissues are within the published normal range $(2.3-3.2 \mu \mathrm{mol} / \mathrm{g}$ tissue) [50]. The results obtained for LVV-hemorphin-7 have been compared with results obtained in an earlier electrospray MS assay of the same extracts [49] and the spiked control samples gave the expected elevation in LVV-hemorphin-7 relative to their respective unspiked counterparts, indicating that assay accuracy is acceptable.

The assay for epinephrine and norepinephrine in adrenal tissue gave mean values of $517 \pm 213$ and $414 \pm$ $157 \mathrm{nmol} / \mathrm{g}$ tissue for three tissue samples (published mean values are 2700 and $600 \mathrm{nmol} / \mathrm{g}$, respectively [51]). Because some of the samples were collected from cases of accidental death, epinephrine dumping to the circulatory system may have occurred during the last moments of life, lowering the adrenal epinephrine content from its usual level.

The concentrations of HVA determined in urine by MALDI-TOFMS are comparable to values obtained by independent analysis. The correlation coefficient indicates that accurate values can be obtained for low mass analytes after minimal sample work-up, despite the presence of contaminant and matrix ions.

\section{Signal Saturation, Analysis Time, and Instrument Dynamic Range}

Avoiding signal saturation is a key concern with quantitative MALDI-TOFMS. If either the analyte or internal standard signal saturates for one or more laser shots, imprecision is introduced. The problem stems from two sources: The limited dynamic range of the instrument's digitizer, and the unpredictable and large shot-to-shot signal intensity variation seen with some samples. Rejection of composite intensity-averaged spectra, with intensities near to the saturation limit, does not eliminate the contributions of saturated data from individual laser shots. Two satisfactory approaches to minimizing or eliminating saturated data have been evaluated.

However, real solutions to the saturation issue lie in improvement of digitizer dynamic range and minimization of shot-to-shot intensity variations for a given laser power. Digitizer design is always a compromise between sampling rate, dynamic range, and price. Fortunately, the availability of units offering high sampling rates and dynamic ranges is continually improving and becoming more cost effective. The instrument dynamic 
range issues discussed here are now being resolved by hardware improvements.

\section{Selection of Appropriate Internal Standards}

For peptides and proteins, instrument response becomes less dependent on compound character as molecular weight increases (provided that $\mathrm{pI}$ values are not drastically different). $\beta$-Lactoglobulin and $\mathrm{rGH}$ are very different but gave signals of similar intensity for equimolar solutions. By way of contrast, epinephrine and norepinephrine are relatively similar in structure, but the instrument molar response ratio is 10:1. Internal standard selection is therefore critical at low mass, and here stable isotopomers are clearly the ideal choice. In additional work (data not shown) we have compared variation in the analyte/internal standard ratio using ${ }^{2} \mathrm{H}$ versus ${ }^{13} \mathrm{C}$ and ${ }^{15} \mathrm{~N}$ isotopomers. The variations observed were not dependent on the label, even in a complex sample matrix.

\section{Low Molecular Weight Species and Accurate Mass Determinations}

Quantification of low molecular weight compounds by MALDI-TOFMS is potentially powerful and this was illustrated in the assays for the catecholamines, in particular, for norepinephrine. In all of the low molecular weight assays the spectra were acquired at the fastest sampling rate available on the digitizer. We also reduced the accelerating voltage from the usual 25 to 7 $\mathrm{kV}$. This gave ion intensities similar to those seen at full accelerating voltage but allowed a greater number of digital samples over the peaks of interest. In this way the peak shape was better described and a more precise mass value was assigned.

\section{Attributes of the Technique and Potential Areas of Application}

The determination of unique elemental composition for unknown analytes, along with absolute quantitative data may be valuable in both clinical and environmental analyses. These situations often require speed, minimal sample work-up, high specificity, and simplicity of operation. Precision is sometimes less of a concern. For example, in screening procedures where the analyte is present in huge excess for abnormal cases, and speed is very important, quantification by MALDI-TOFMS may offer an ideal approach: Fast, specific, and sensitive.

Determinations involving high molecular weight biomolecules-where electrospray mass spectrometry would present complex spectra due to multiple charging effects-quantitative MALDI-TOFMS can prove useful. The predominance of the singly charged species in a complex mixture enables easier interpretation of spectra, and the ability of MALDI-TOFMS to analyze complex biological samples aids in eliminating the need for chromatographic steps.

\section{Acknowledgments}

This work was funded in part by a grant from the Australian Research Council. The authors thank Cambridge Isotope Laboratories for their generous support of this work through its stable isotope research grant program. They also thank: Mr. Ray Williams for his support; Associate Professor Bernie Tuch for his gift of pancreatic tissues and human insulin standard; Dr. Minoti Apta, Gastroenterology Unit, Prince of Wales Hospital (Sydney), for the rats used in this study; Professor John Hilton, Institute of Forensic Medicine (Sydney) for the supply of normal human adrenal glands, and Dr. Lyn Tobiansky, Department of Clinical Pathology, St. Vincent's Hospital (Sydney), for collection and classification of pheochromocytoma.

\section{References}

1. Marie, A.; Fournier, F.; Tabet, J. C. Characterization of Synthetic Polymers by MALDI-TOF/MS: Investigation into New Methods of Sample Target Preparation and Consequence on Mass Spectrum Finger Print. Anal. Chem. 2000, 72, 5106-5114.

2. Wu, K. J.; Odom, R. W. Characterizing Synthetic Polymers by MALDI MS. Anal. Chem. 1998, 70, 456A-461A.

3. Zaluzec, E. J.; Gage, D. A.; Watson, J. T. Matrix-Assisted Laser Desorption Ionization Mass Spectrometry: Applications in Peptide and Protein Characterization. Protein Expr. Purif. 1995, 6, 109-123.

4. Roepstorff, P. MALDI-TOF Mass Spectrometry in Protein Chemistry. Exs. 2000, 88, 81-97.

5. Nguyen, D. N.; Becker, G. W.; Riggin, R. M. Protein Mass Spectrometry: Applications to Analytical Biotechnology. J. Chromatogr. A. 1995, 705, 21-45.

6. Miketova, P.; Schram, K. H. Mass Spectrometry of Nucleotides and Oligonucleotides. Mol. Biotechnol. 1997, 8, 249-253.

7. Faulstich, K.; Worner, K.; Brill, H.; Engels, J. W. A Sequencing Method for RNA Oligonucleotides Based on Mass Spectrometry. Anal. Chem. 1997, 69, 4349-4353.

8. Bentzley, C. M.; Johnston, M. V.; Larsen, B. S.; Gutteridge, S. Oligonucleotide Sequence and Composition Determined by Matrix-Assisted Laser Desorption/Ionization. Anal. Chem. 1996, 68, 2141-2146.

9. Kanazawa, K.; Ashida, K.; Itoh, M.; Nagai, H.; Sasaki, H.; Fukuda, M. Establishment of a Method for Mapping of N-Linked Oligosaccharides and Its Use to Analyze Industrially Produced Recombinant Erythropoietin. Biol. Pharm. Bull. 1999, 22, 339-346.

10. Villanueva, J.; Canals, F.; Querol, E.; Aviles, F. X. Monitoring the Expression and Purification of Recombinant Proteins by MALDI-TOF Mass Spectrometry. Enzyme Microb. Technol. 2001, 29, 99-103.

11. Li, L.; Garden, R. W.; Sweedler, J. V. Single-Cell MALDI: A New Tool for Direct Peptide Profiling. Trends Biotechnol. 2000, 18, 151-160.

12. Li, L.; Garden, R. W.; Romanova, E. V.; Sweedler, J. V. In Situ Sequencing of Peptides from Biological Tissues and Single Cells Using MALDI-PSD/CID Analysis. Anal. Chem. 1999, 71, 5451-5458.

13. Lynn, E. C.; Chung, M. C.; Tsai, W. C.; Han, C. C. Identification of Enterobacteriaceae Bacteria by Direct Matrix-Assisted Laser Desorptiom/Ionization Mass Spectrometric Analysis of Whole Cells. Rapid Commun. Mass Spectrom. 1999, 13, 20222027. 
14. Stoeckli, M.; Farmer, T. B.; Caprioli, R. M. Automated Mass Spectrometry Imaging with a Matrix-Assisted Laser Desorption Ionization Time-of-Flight Instrument. J. Am. Soc. Mass Spectrom. 1999, 10, 67-71.

15. Stoeckli, M.; Chaurand, P.; Hallahan, D. E.; Caprioli, R. M. Imaging Mass Spectrometry: A New Technology for the Analysis of Protein Expression in Mammalian Tissues. Nat. Med. 2001, 7, 493-496.

16. Caprioli, R. M.; Farmer, T. B.; Gile, J. Molecular Imaging of Biological Samples: Localization of Peptides and Proteins Using MALDI-TOF MS. Anal. Chem. 1997, 69, 4751-4760.

17. Chaurand, P.; Stoeckli, M.; Caprioli, R. M. Direct Profiling of Proteins in Biological Tissue Sections by MALDI Mass Spectrometry. Anal. Chem. 1999, 71, 5263-5270.

18. Jespersen, S.; Chaurand, P.; van Strien, F. J.; Spengler, B.; van der Greef, J. Direct Sequencing of Neuropeptides in Biological Tissue by MALDI-PSD Mass Spectrometry. Anal. Chem. 1999, 71, 660-666.

19. Kazmaier, T.; Roth, S.; Zapp, J.; Harding, M.; Kuhn, R. Quantitative Analysis of Malto-Oligosaccharides by MALDITOF Mass Spectrometry, Capillary Electrophoresis, and Anion Exchange Chromatography. Fres. J. Anal. Chem. 1998, 361, 473-478.

20. Ling, Y. C.; Lin, L.; Chen, Y. T. Quantitative Analysis of Antibiotics by Matrix-Assisted Laser Desorption/Ionization Time-of-Flight Mass Spectrometry. Rapid Commun. Mass Spectrom. 1998, 12, 317-327.

21. Abell, D. C.; Sporns, P. Rapid Quantitation of Potato Glycoalkaloids by Matrix-Assisted Laser Desorption/Ionization Time-of-Flight Mass Spectrometry. J. Ag. Food Chem. 1996, 44, 2292-2296.

22. Bruenner, B. A.; Yip, T. T.; Hutchens, T. W. Quantitative Analysis of Oligonucleotides by Matrix-Assisted Laser Desorption/Ionization Mass Spectrometry. Rapid Commun. Mass Spectrom. 1996, 10, 1797-1801.

23. Muddiman, D. C.; Gusev, A. I.; Martin, L. B.; Hercules, D. M. Direct Quantification of Cocaine in Urine by Time-of-Flight Mass Spectrometry. Fres. J. Anal. Chem. 1996, 354, 103-110.

24. Gusev, A. I.; Wilkinson, W. R.; Proctor, A.; Hercules, D. M. Direct Quantitative Analysis of Peptides Using Matrix Assisted Laser Desorption Ionization. Fres. J. Anal. Chem. 1996, 354, 455-463.

25. Tang, X. D.; Sadeghi, M. E.; Olumee, Z.; Vertes, A.; Braatz, J. A.; Mcllwain, L. K.; Dreifuss, P. A. Detection and Quantitation of $\beta$-2-Microglobulin Glycosylated End Products in Human Serum by Matrix-Assisted Laser Desorption/Ionization Mass Spectrometry. Anal. Chem. 1996, 68, 3740-3745.

26. Jespersen, S.; Niessen, W. M. A.; Tjaden, U. R.; van der Greef, J. Quantitative Bioanalysis Using Matrix-Assisted Laser Desorption/Ionization Mass Spectrometry. J. Mass Spectrom. 1995, 30, 357-364.

27. Muddiman, D. C.; Gusev, A. I.; Stoppeklangner, K.; Proctor, A.; Hercules, D. M.; Tata, P.; Venkataramanan, R.; Diven, W. Simultaneous Quantification of Cyclosporin A and Its Major Metabolites by Time-of-Flight Secondary-Ion Mass Spectrometry and Matrix-Assisted Laser Desorption/Ionization Mass Spectrometry Utilizing Data Analysis Techniques-Comparison with High-Performance Liquid Chromatography. J. Mass Spectrom. 1995, 30, 1469-1479.

28. Nelson, R. W.; McLean, M. A.; Hutchens, T. W. Quantitative Determination of Proteins by Matrix-Assisted Laser Desorption Ionization Time-of-Flight Mass Spectrometry. Anal. Chem. 1994, 66, 1408-1415.

29. Muddiman, D. C.; Gusev, A. I.; Proctor, A.; Hercules, D. M.; Venkataramanan, R.; Diven, W. Quantitative Measurement of Cyclosporin A in Blood by Time-of-Flight Mass Spectrometry. Anal. Chem. 1994, 66, 2362-2368.
30. Tang, K.; Allman, S. L.; Jones, R. B.; Chen, C. H. Quantitative Analysis of Biopolymers by Matrix-Assisted Laser Desorption. Anal. Chem. 1993, 65, 2164-2166.

31. Harvey, D. J. Quantitative Aspects of the Matrix-Assisted Laser Desorption Mass Spectrometry of Complex Oligosaccharides. Rapid Commun. Mass Spectrom. 1993, 7, 614-619.

32. Gusev, A. I.; Wilkinson, W. R.; Proctor, A.; Hercules, D. M. Quantitative Analysis of Peptides by Matrix-Assisted Laser Desorption Ionization Time-of-Flight Mass Spectrometry. Appl. Spectrosc. 1993, 47, 1091-1092.

33. Duncan, M. W.; Matanovic, G.; Cerpa-Poljak, A. Quantitative Analysis of Low Molecular Weight Compounds of Biological Interest by Matrix-Assisted Laser Desorption Ionization. Rapid Commun. Mass Spectrom. 1993, 7, 1090-1094.

34. Horak, J.; Werther, W.; Schmid, E. R. Optimization of the Quantitative Determination of Chlormequat by Matrix-Assisted Laser Desorption/Ionization Mass Spectrometry. Rapid Commun. Mass Spectrom. 2001, 15, 241-248.

35. Gobom, J.; Kraeuter, K. O.; Persson, R.; Steen, H.; Roepstorff, P.; Ekman, R. Detection and Quantification of Neurotensin in Human Brain Tissue by Matrix-Assisted Laser Desorption/ Ionization Time-of-Flight Mass Spectrometry. Anal. Chem. 2000, 72, 3320-3326.

36. Wang, J.; Sporns, P. MALDI-TOF MS Quantification of Coccidiostats in Poultry Feeds. J. Agric. Food Chem. 2000, 48, 2807-2811.

37. Desiderio, D. M.; Wirth, U.; Lovelace, J. L.; Fridland, G.; Umstot, E. S.; Nguyen, T. M.; Schiller, P. W.; Szeto, H. S.; Clapp, J. F. Matrix-Assisted Laser Desorption/Ionization Mass Spectrometric Quantification of the Mu Opioid Receptor Agonist Damgo in Ovine Plasma. J. Mass Spectrom. 2000, 35, 725-733.

38. Wu, J.; Chatman, K.; Harris, K.; Siuzdak, G. An Automated MALDI Mass Spectrometry Approach for Optimizing Cyclosporin Extraction and Quantitation. Anal. Chem. 1997, 69, 3767-3771.

39. Nicola, A. J.; Gusev, A. I.; Proctor, A.; Jackson, E. K.; Hercules, D. M. Application of the Fast-Evaporation Sample Preparation Method for Improving Quantification of Angiotensin II by Matrix-Assisted Laser Desorption/Ionization. Rapid Commun. Mass Spectrom. 1995, 9, 1164-1171.

40. Wang, J.; Sporns, P. Analysis of Anthocyanins in Red Wine and Fruit Juice Using MALDI-MS. J. Agric. Food Chem. 1999, 47, 2009-2015.

41. Wang, J.; Sporns, P.; Low, N. H. Analysis of Food Oligosaccharides Using MALDI-MS: Quantification of Fructooligosaccharides. J. Agric. Food Chem. 1999, 47, 1549-1557.

42. Jiang, G.; Vasanthan, T. MALDI-MS and Hplc Quantification of Oligosaccharides of Lichenase-Hydrolyzed Water-Soluble $\beta$-Glucan from Ten Barley Varieties. J. Agric. Food Chem. 2000, 48, 3305-3310.

43. Wang, J.; Kalt, W.; Sporns, P. Comparison between HPLC and MALDI-TOF MS Analysis of Anthocyanins in Highbush Blueberries. J. Agric. Food Chem. 2000, 48, 3330-3335.

44. Yang, Y.; Chien, M. Characterization of Grape Procyanidins Using High-Performance Liquid Chromatography/Mass Spectrometry and Matrix-Assisted Laser Desorption/Ionization Time-of-Flight Mass Spectrometry. J. Agric. Food Chem. 2000, 48, 3990-3996.

45. Wittmann, C.; Heinzle, E. MALDI-TOF MS for Quantification of Substrates and Products in Cultivations of Corynebacterium Glutamicum. Biotechnol. Bioeng. 2001, 72, 642-647.

46. Mirgorodskaya, O. A.; Kozmin, Y. P.; Titov, M. I.; Korner, R.; Sonksen, C. P.; Roepstorff, P. Quantitation of Peptides and Proteins by Matrix-Assisted Laser Desorption/Ionization Mass Spectrometry Using (18)O-Labeled Internal Standards. Rapid Commun. Mass Spectrom. 2000, 14, 1226-1232. 
47. Bahr, U.; Stahl-Zeng, J.; Gleitsmann, E.; Karas, M. Delayed Extraction Time-of-Flight MALDI Mass Spectrometry of Proteins above 25,000 Da. J. Mass Spectrom. 1997, 32, 1111-1116.

48. Takach, E. J.; Hines, W. M.; Patterson, D. H.; Juhasz, P.; Falick, A. M.; Vestal, M. L.; Martin, S. A. Accurate Mass Measurements Using MALDI-TOF with Delayed Extraction. J. Protein Chem. 1997, 16, 363-369.

49. Cerpa-Poljak, A.; Lahnstein, J.; Mason, K. E.; Smythe, G. A.; Duncan, M. W. Mass Spectrometric Identification and Quan- tification of Hemorphins Extracted from Human Adrenal and Pheochromocytoma Tissue. J. Neurochem. 1997, 68, 1712-1719.

50. Dickerman, E.; Dickerman, S.; Meites, J. Influence of Age, Sex, and Estrous Cycle on Pituitary and Plasma Growth Hormone Levels in Rats. In Growth and Growth Hormone-International Symposium on Growth Hormone; Pecile, A.; Muller, E. E., Eds.; Excerpta Medica: Amsterdam, 1971; p 252-260.

51. Soffer, L. J.; Doffman, R. I.; Gabrilove, J. L. The Human Adrenal Gland; Lea and Febiger: Philadelphia, 1961; p 117. 